$12-2019$

\title{
Soil Characteristics Drive Ficaria verna Abundance and Reproductive Output
}

\author{
Justin P. Kermack \\ Cleveland State University \\ Emily Rauschert \\ Cleveland State University, e.rauschert@csuohio.edu
}

Follow this and additional works at: https://engagedscholarship.csuohio.edu/scibges_facpub

Part of the Biology Commons, and the Weed Science Commons

How does access to this work benefit you? Let us know!

\section{Recommended Citation}

Kermack, Justin P. and Rauschert, Emily, "Soil Characteristics Drive Ficaria verna Abundance and Reproductive Output" (2019). Biological, Geological, and Environmental Faculty Publications. 102.

https://engagedscholarship.csuohio.edu/scibges_facpub/102

This Article is brought to you for free and open access by the Biological, Geological, and Environmental Sciences Department at EngagedScholarship@CSU. It has been accepted for inclusion in Biological, Geological, and Environmental Faculty Publications by an authorized administrator of EngagedScholarship@CSU. For more information, please contact library.es@csuohio.edu. 


\title{
Soil characteristics drive Ficaria verna abundance and reproductive output
}

\author{
Justin P. Kermack and Emily S. J. Rauschert ${ }^{2}$ (B)
}

\section{Keywords:}

Invasion success; site characteristics; soil characteristics

\section{Author for correspondence:}

Emily S. J. Rauschert. Department of Biological. Geologital and Environmental Stientes, Cleveland State University, 2121 Euclid Avenue, Cleveland, $\mathrm{OH} 44115$.

(Email: e.rauschert@icsuohio.edu)

\begin{abstract}
Lesser celandine (Ficaria verna Huds.), an invasive plant from Europe, is beconing widespread in river valleys throughout the northeastern United States and the Pacific Northwest. Its high rate of asexual bulbil and tuber production creates dense infestations threatening native spring ephemerals. Ficaria verna abundance and reproductive output (seeds, bulbils, and tubers) were examined in invaded transects spanning a disturbance gradient away from a river. Site char. acteristics (photosynthetically active radiation $[\mathrm{PAR}]$, soil $\mathrm{pH}$, moisture, texture, and nutrients) were quantified to examine their roles in plant abundance and reproduction. A larger-scale study examined random transects not specifically chosen based on $F$. verna infestations. Soil characteristics and slope were hypothesized to drive $F$. verna abundance and reproduction; we also hypothesized that reproductive output and biomass would be highest at intermediate distances from rivers, where disturbances are infrequent. Ficaria verna abundance and reproductive output varied considerably by site; soil characteristics, rather than landscape placement, appeared to drive plant abundance and reproduction. Lower percent sand was associated with significantly higher $F$. verna stem density and bulbil and tuber production. CEC was significantly negatively related to $F$. verna biomass and tuber counts. In the larger-scale survey, slope and PAR were significantly negatively related to $F$. verna presence and percent cover, respec. tively, Overall, these findings suggest that soil texture and slope can help explain higher abundance and reproductive outputs. However, reproductive output and biomass were not significantly greater at intermediate distances, contrary to expectations. We did not observe any seed production in any of the plots, although we did see a few plants with seeds outside our study area in the second year, demonstrating a near-complete reliance on asexual reproduction in these populations. This study expands on the current limited understanding of F. verna and can help management by identifying areas likely to support dense infestations.
\end{abstract}

\section{Introduction}

Because resources to manage invasive plants are limited, managers are tasked with prioritizing management efforts. Early recognition and removal of potentially harmful species are incredibly important for effective control of invasions. The longer an invasion persists, the more difficult and costly it is to manage, requiring increasing amounts of resources and effort (Hobbs and Humphries 1995). Invasive plants are not always harmful in all environments, and being able to identify the most susceptible environments for invasion is crucial for focused management and control efforts (Roxburgh et al. 2004). Therefore, to manage invasive plants more effectively, we need a greater understanding of their ideal habitats, dispersal mechanisms, and interactions with the local environment.

Soil characteristics can strongly impact plant communities and species performance. For example, soil pH can influence the availability of plant nutrients considerably and can limit plant growth, especially under increasing acidity (Kidd and Proctor 2001). Soil variables may influence invasive and native plants in a similar way, yet the intensity of influence varies by species (Porazinska et al. 2003). Variation in the influence of soil characteristics on plants can make generalizing and predicting trends very difficult (Porazinska et al. 2003). As we better understand the underlying mechanisms of invasion and its consequences, we are better able to detect threats and protect native ecosystems.

Beyond the species-specific requirements of particular invasions, some areas are more susceptible to invasion in general than others, especially areas of high disturbance. Roads, for example, have strong associations with invasion, as they provide a means for long-distance transportation (Mortensen et al, 2009). River flooding can drastically alter the landscape, and disturbances have been shown to influence the species richness of riparian plants (Lite et al. 2005). Disturbances also create opportunities for invasive plans to capitalize on available resources, including open space. For example, the prolific spread of Japanese knotweed (Reynoutria japonica Houtt.) and reed canary grass (Phalaris artudinacea L.) has been aided by changes in 


\section{Management Implications}

One of the difficulties in the management of Ficaria verna (lesser celandine) is the lack of information about its basic biology and demography; it is a difficult task to manage a species that is not fully understood. This spring ephemeral reproduces primarily via bulbils, an unusual method of asexual reproduction. Invasive plants such as $F$. verna often display large variations in reproductive output, which can make management prioritization difficult. A lack of knowledge of $F$. verna reproductive output and population growth limits our ability to prioritize management based on which environments are most susceptible to invasion.

Soil characteristics appear to play a large role in driving the population performance of $F$, verna and should be considered to help prioritize the allocation of resources for management. Significant negative relationships were found in this study between $F$. verna abundance and reproduction and percent sand, possibly driven by low soil moisture. Low-slope areas are also likely to have more F. verna. These characteristics can be used to identify high-risk populations for immediate management. Management will be most effective in combating population spread by targeting sites where high reproductive output is likely.

In addition to reproductive potential, it is also important to consider where spread is most likely to occur. Areas close to a river are extremely important with regard to population spread and may also require management. While $F$. verta abundance and reproduction generally were not highest near the river, there was still considerable bulbil prodution right at the river, where flooding is likely to transport bulbils, which remain on the soil surface after the plant dies back. Overall, the highest-priority sites for management are in floodplains with less sandy soils and a low slope gradient.

It is imperative to gain a greater understanding of this perennial in order to more efficiently manage and control its spread. Because $F$. verna is not well established at this point in all areas, effective management could still prevent it from becoming widely established, at which point management costs and control efforts would increase considerably. Moreover, it appears that native communities can recover to some extent following $F$. vernt removal (J. Hillmer, personal communication). Management should focus efforts on reducing the spread by focusing on two key areas: areas where $F$. verna is likely to grow well, and areas likely to be a source for future spread, such as near rivers that flood regularly. In less-invaded areas, soil and elevation maps could be used to prioritize certain populations for management or predict critical areas that may be suitable for and susceptible to $F$. vema invasion in future.

disturbance regimes that alter competitive interactions and resource availability in favor of alien species, resulting in reduced native plant diversity and abundance (Jose et al. 2013). Many invasives grow along transport-disturbance corridors such as roads and river systems, and managers need a better understanding of plant reproduction in such environments, which likely drive regional spread.

Spring ephemeral plant communities are under increasing threat from invasive plant species and are often outcompeted to critically low levels (Axtell et al. 2010), In river valleys in the northeastern and Pacific Northwest regions of the United States, a threat to native communities has emerged, lesser celandine [Ficaria verna (Huds.), syn: Rantuncults ficaria L.; Ranunculaceae]. It is a spring ephemeral itself, which is unusual for an invasive, because it disappears for parts of the year, potentially facilitating the growth of other plants. Ficaria verna can form dense monocultures, threatening local biodiversity (Axtell et al. 2010; Swearingen 2005). Its presence has been associated with an increase in pollinator visits to two native spring ephemerals, narrowleaf spring-beauty (Claytonia virginica L.) and cutleaf toothwort [Cardamine concatenata (Michx.) Swi], but invaded plots ultimately had decreased seed set of both native plants (Masters and Emery 2015b). Ficaria vema presence can also lead to decreased biomass and recruitment of nearby competitors such as grass species (Masters and Emery 2016).

Flooding events and river systems likely play an important role in explaining the spread of this invasive species through transportation and deposition of propagules. While F. verna can be found on steeper, drier slopes and in sunny spots with low canopy cover, there is evidence that it prefers moist floodplain in shaded areas, with higher levels of disturbances (Axtell et al. 2010). These conditions are common at intermediate distances from rivers. Because F. vema dies back early in the growing season, its presence on steeper slopes could lead to more soil erosion later in the year.

The aim of this study was to examine the relationship between site characteristics and the abundance and reproductive output of F. verna along a disturbance gradient away from a river. To accomplish this, biomass, reproductive output, and site characteristics were measured at various infested sites along the Rocky River in northeastern Ohio, USA. An additional larger-scale study was conducted examining $F$. verna abundance and reproduction along a longer portion of the river without specifically targeting infested areas. Soil texture, nutrient availability, and slope were hypothesized to play an important role in determining successful $F$. verna populations. We also hypothesized that $F$. verna abundance and reproduction would be highest at intermediate distances from the river.

\section{Materials and Methods}

\section{Study Species}

Ficaria verna is native to Europe and parts of Asia and is mainly found in floodplains and wetland lowlands; it can also be found in drier, woodier highlands. Ficaria verna has an early, yet brief growing season; it germinates in spring around March and April, or sometimes even earlier under the snow in winter, and top growth completely dies back in the early summer around June and July (Axtell et al. 2010). In northeast Ohio, we have observed bulbil germination as early as December (although growth is halted when covered by snow). During senescence around late June, large portions of land are left barren, making them susceptible to invasion by a host of weedy species (Axtell et al. 2010). Ficaria vema is not as palatable as its competitors for many herbivores, which contributes to its competitive advantage (Axtell et al. 2010),

Ficaria verna may be a particularly successful invasive due to its multiple reproductive strategies; besides forming seeds, it also produces tubers and aboveground bulbils. Under intermediate disturbance, $F$. verna invests more heavily in the production of seeds (Jung et al. 2008). When resources are not readily available for sexual reproduction, asexual bulbils are produced in place of seeds, and in some cases, the amount of bulbils produced is inversely related to the amount of seeds produced (Arizaga and 
Ezcurra 1995). Because the invasion is thought to have started from a deliberately planted patch in one landowner's property, the Rocky River populations may be clones incapable of sexual reproduction. This may lead to further selection for traits that decrease sexual fertility (Barrett 2015). Not all subspecies of $F$. verna produce tubers, which are another important dispersal mechanism with high germination rates (Kertabad et al. 2013), but in our study, only Ficaria verna ssp. bulbifer, was present in the survey area.

\section{Ficaria verna-focused Transect Stwdy (2015 and 2016)}

Ficaria verna biomass and seed, bulbil, and tuber production rates were examined along the river valley of the Rocky River Reservation in the Cleveland Metroparks in Cleveland, $\mathrm{OH}$ $\left(41.40902^{\circ} \mathrm{N}, 81.88399^{\circ} \mathrm{W}\right)$. The Rocky River Reservation was chosen because it has the highest infestation of $F$. verna in Cuyahoga County (Cleveland Metroparks Invasive Plant Atlas 2016). In 2008, the Rocky River Reservation had more than 183 acres of $F$. verta where cover was greater than $50 \%$ (Mack 2008). This reservation provides a large array of recreational services from hiking trails and picnic sites to golf courses. It mainly consists of floodplain deciduous forests, wetlands, and meadow with a variety of wildlife and bird species year-round. The dominant tree species include willow (Salix spp), American sycamore (Platanus occidentalis L.), American beech (Fagus grandifolia Ehrh.), and maple (Acer spp).

Six sample sites were selected in 2015 , with an additional two sites added in 2016, spanning a portion of the Rocky River, to explore abundance and reproductive outputs while ensuring varying site characteristics. Sites were selected in floodplains with an $F$. verna population extending at least $25 \mathrm{~m}$ away from the river, as is common along this watershed, while attempting to mitigate any anthropogenic disturbances such as trails or paths as much as possible. There were often anthropogenic alterations around 10- to $20-\mathrm{m}$ quadrats away from the river, in the form of hiking trails or footpaths, throughout the Rocky River Reservation. Sample sites had no management applied in the last 2 yr.

\section{Experimental Design}

A transect was set up perpendicular to the river at each of the six sites in 2015 , starting from the vegetation nearest the riverbank and extending away from the river, to represent a disturbance (flooding) gradient. In early May, midway through the growing season, 20 by $20 \mathrm{~cm}$ quadrats were set up along each transect at $0,5,10,15$, 20 , and $25 \mathrm{~m}$ away from the stream bank to evaluate the $F$. verna aboveground biomass, stem density, and reproductive output (bubil and tuber production). Within each of these quadrats, 10 plants were removed at coordinates selected using a random number generator. Bulbils were counted and weighed, and the length of each plant removed was measured. The total number of stems within each quadrat was then quantified to estimate density. In addition to the 10 individual plants sampled, once bulbils had fully formed, 10 additional plants per quadrat were selected at random from each quadrat for destructive sampling to quantify biomass and bulbil and tuber production. The average aboveground plant biomass was calculated for the 10 randomly removed stems, which were dried for $2 \mathrm{~d}$ at $60 \mathrm{C}$ in a drying oven (Fisher Scientific, Waltham, MA) before being weighed.

In 2015, the populations at some sites extended beyond 20 to $25 \mathrm{~m}$; we therefore extended the transect length by $10 \mathrm{~m}$ in 2016 and resampled all sites to gain a greater understanding of the plant dynamics at distances farther from the Rocky River. Two additional sample sites were also added, following the same site-selection process as in 2015, with an additional goal to include sites south of Site 1

\section{Site Characteristics}

Distance from the river, $\mathrm{PAR}$, soil characteristics $(\mathrm{pH}$, percent moisture, and nutrient analysis), slope, and aspect were recorded at each site. PAR measurements were taken in late April during the peak growing season (Apogee Instruments, Logan, UT), as close to noon as possible on a cloudless day, In April 2016, two 15-cm soil cores were also taken from each quadrat; soil moisture content was measured for each sample in the lab. Soil texture (particle-size analysis) was also investigated using the hydrometer method (Gee and Bauder 1979). Nutrient analyses involving phosphorus, potassium, calcium, magnesium, CEC, pH, lime test index (a measure of reserve acidity), and total nitrogen were performed by the STAR laboratory at the Ohio State University. Due to additional costs associated with testing, nitrate nitrogen levels were only assessed for every other quadrat along the transect.

\section{Large-Scale Survey}

A larger-scale survey was conducted to gain more insight into the impact of site characteristics on $F$. verna presence and performance without bias toward sites with $F$. vema present. The random point generator in ArcMap v. 10.3.1 (Environmental Systems Research Institute, Redlands, CA, USA) was used to identify 30 random sample points along the river.

At each sample site, a $30-\mathrm{m}$ transect was set up as close to the randomly generated point as possible, perpendicular to the river (avoiding large fallen trees, paths, or any other major impedance on transect.) Sampling was conducted at the $0-, 15-$, and $30-\mathrm{m}$ marks along the $30-\mathrm{m}$ transect, representing close, intermediate, and far distances from the river. In some sites, due to the presence of steep cliffs, there were no $15-$ and $30-\mathrm{m}$ plots available. Ficaria verna percent cover and above ground biomass were measured at each of the three distances from the river. We used 2 by $2 \mathrm{~m}$ for estimating percent cover based on visual percentage estimates and for categorization according to Daubenmire's (1959) cover classes: $0 \%$ to $5 \%, 5 \%$ to $25 \%, 25 \%$ to $50 \%, 50 \%$ to $75 \%, 75 \%$ to $95 \%$, and $95 \%$ to $100 \%$. Ficaria vema aboveground biomass was collected from 50 by $50 \mathrm{~cm}$ quadrats at each sampling location, dried in a drying oven for $2 \mathrm{~d}$, and weighed. Site characteristics measured include canopy cover, slope angle, and aspect. PAR was measured at each plot along the transect.

\section{Analysis}

Generalized linear mixed-effect models were used to analyze the data, and all analyses were conducted in R, using the LME4, LMERTEST, and MASS packages (Bates et al. 2015; Kuznetsova et al. 2017; R Development Core Team 2011; Venables and Ripley 2002). The results were similar in both years, and the analyses presented here focus on the 2016 data, which involved surveying two additional sites and longer transects. Site was included as a random factor in all final models for both surveys.

In the $F$. verna-focused transect survey, the following response variables were all analyzed separately: plant biomass, the number of stems per square meter, and the average number of bulbils and tubers per plant. Initially, linear mixed-effect models were fit using LMER; however, in several cases, diagnostic plotting indicated strong 
heteroscedacity. Log transformations were applied for plant biomass and for count or count-like data, Poisson/quasipoisson regression models were fit using glmmPQL from the MASS package.

To test whether there was a relationship between the plant response variables and the distance of plots from the river, we conducted ANOVAs with the distance classes as a categorical variable (due to expected nonlinear increase with distance). Because the distance from the river was likely related to changes in environmental variables, especially soil characteristics, we assessed the relationship between site variables and $F$, verna abundance and reproduction in separate models. The following environmental variables were initially considered: $\mathrm{PAR}$, soil $\mathrm{pH}$, percent soil moisture, $\mathrm{P}, \mathrm{K}, \mathrm{N}, \mathrm{Ca}, \mathrm{Mg}$ levels, CEC, and soil texture (percent sand, silt, and clay). Multicollinearity was detected in the soil variables using correlation tests and by examining variance inflation factors. Percent sand was chosen as the most likely important soil texture variable in this system, as $F$. verna generally requires moist soils. As expected, sand was inversely correlated with nitrogen and lower soil moisture. CEC was chosen to represent all the base cations together. The remaining environmental variables were $P A R$, soil $\mathrm{pH}$, log-transformed $\mathrm{P}, \mathrm{CEC}$, and percent sand. In models involving just these variables, variance inflation factors were all below the recommended level of 4 (Zuur et al. 2009).

Following the approach of Zuur et al. (2009), full models were fit using all the candidate variables, and graphical analysis, including diagnostic plots of residuals versus each explanatory factor, was used to determine whether two-way interactions were needed in the models. Individual explanatory variables were then dropped one by one in a sequential hypothesis-testing approach to determine final models. For linear regressions, the model-selection process was performed using models fit with maximum-likelihood estimation, and final models were then fit using restricted maximum-likelihood estimation (Zuur et al. 2009). Models were validated by plotting residuals against fitted values and by examining Q-Q plots of the residuals to assess model bomogeneity of variances and normality. We also examined the pattern in the residuals versus all explanatory variables. If the simplified model had poorer fit, then the last dropped variable was included in the final model, even if not statistically significant.

In the large-scale study, because the design was not specifically targeted at known $F$. verna populations, logistic regression was first used to model $F$. verna presence/absence, including plots with no $F$. verna present. For plots with $F$. verna present, we modeled the percent cover of $F$. verta as a function of distance from the river and broader-scale environmental variables, using Poisson regression. We then modeled $F$. verna biomass, which again required log transformation due to strong nonhomogeneity of variance. The candidate explanatory variables were distance from the river $(0,15,30 \mathrm{~m})$, slope, aspect, PAR, and canopy cover. As before, distance from the river was treated as a categorical variable to allow for possible nonlinear response. Slope and PAR required log transformation. Aspect was transformed to two variables, southness and eastness, ranging from -1 to 1 . No multicollinearity was detected between these response variables using graphical analysis or examination of variance inflation factors.

\section{Results and Discussion}

\section{Ficaria verna-focused Transect Survey}

Ficaria verna abundance and reproduction were variable between sample sites during both years of field observations (coefficient of variation for the number of $F$. verna stems $\mathrm{m}^{-2}=54.9$, coefficient of variation for $F$. verna biomass $=75.6$ ). Densities of $F$. verna were found to be as high as 11,425 plants $\mathrm{m}^{-2}$ in some areas, with an overall mean of 2,772 plants $\mathrm{m}^{-2}$ (maximum $=11,425$, median $=2,412$ ). This maximum was an outlier, with a large number of small $F$. verna plants. The number of $F$. verna stems per square meter was significantly negatively related to percent sand, $t=-2.61, \mathrm{df}=52$, $\mathrm{P}=0.012$, slope $=-0.01 ;$ Figure 1). The final model also included a nonsignificant positive relationship with log-transformed soil phosphorus $(t=1.74, \mathrm{df}=52, \mathrm{P}=0.088$, slope $=0.15)$ and a nonsignificant negative relationship with $\mathrm{CEC}(\mathrm{t}=-1.611, \mathrm{df}=52$, $\mathrm{P}=0.11$, slope $=-0.026$; Figure 2).

For plant biomass, there was a significant negative effect of $\mathrm{CEC}(\mathrm{F}(1,57.3)=4.57, \mathrm{P}=0.037)$, and a significant interaction of $\mathrm{pH}$ and $C E C(F(1,57.0)=4.91, \mathrm{P}=0.031)$. The final model also included $\mathrm{pH}(F(1,57.8)=3.80, \mathrm{P}=0.056)$, percent sand $(F(1,57.34)=3.14, \mathrm{P}=0.081)$, and an interaction between percent sand and $\mathrm{pH}(F(1,57.7)=3.13, \mathrm{P}=0.082)$, although these were only marginally significant.

Of the plants sampled over the $2 \mathrm{yr}, 31 \%$ produced bulbils. Bulbil production ranged from 0 to as high as 18 per plant (overall mean $=2.9$ ). Average bulbil production (averaged over 10 plants) ranged from 0 to 6.1 per stem (mean $=1.3$, median $=0.95$ ). Bulbils had an average length of $3.93 \mathrm{~mm}$ and an average mass of $0.0101 \mathrm{~g}$. The average number of bulbils produced per plant was significantly negatively related to percent sand $(t=-2.27$, $d f=55, P=0.027$, slope $=-0.012$ )

Tuber presence ranged from 1 to as high as 11 tubers per plant (mean $=2.4$, median $=2.2, \mathrm{SE}=0.093$ ). The average number of tubers present was 2.3 per plant, with an average tuber length of $7.9 \mathrm{~mm}$ and an average mass of $0.041 \mathrm{~g}$. The average number of tubers produced per plant was significantly negatively related to percent sand $(t=-2.71, \mathrm{df}=54, \mathrm{P}=0.009$, slope $=$ $-0.0089)$ and negatively to $\mathrm{CEC}(\mathrm{t}=-2.32, \mathrm{df}=54, \mathrm{P}=0.024$, slope $=-0.032$ ). Interestingly, there was no seed production observed in any of the sample quadrats.

The distribution of $F$. verna was more sparse near the river ( $0-\mathrm{m}$ quadrats), and then a dense monoculture was typically observed up to the $20-\mathrm{m}$ quadrat. Beyond the $20-\mathrm{m}$ quadrat, there appeared to be higher abundances of other species present. However, in the F. verna-focused transect survey, none of the response variables indicated significant relationships with the distance from the river (all P-values were greater than 0.05 ; Figure 3).

A few sites had a dense mat of $F$. verna extending beyond the farthest quadrat $(25 \mathrm{~m})$, primarily in locations consisting of a well-established, successful population of $F$. verna. Sites with a gentle gradient more often had extended populations beyond the length of the established transect. Sites that rapidly increased in gradient beyond the transect typically also declined in the cover of all vegetation, not just $F$, verna, and steep slopes are often common features throughout river valleys due to erosion over time.

\section{Large-scale Transect Survey}

Ficaria verna was present in $75 \%$ of the random plots surveyed, and present with more than $10 \%$ cover in $53 \%$ of plots. Ficaria verna presence was significantly related to slope $(z=-2.007$, $\mathrm{P}=0.045$, slope $=-0.078$ ) but not to distance from the river (15 m: $z=-0.57, P=0.569$, slope $=-0.398 ; 30 \mathrm{~m}: \quad z=1.30$, $\mathrm{P}=0.193$, slope $=1.29$ ). 

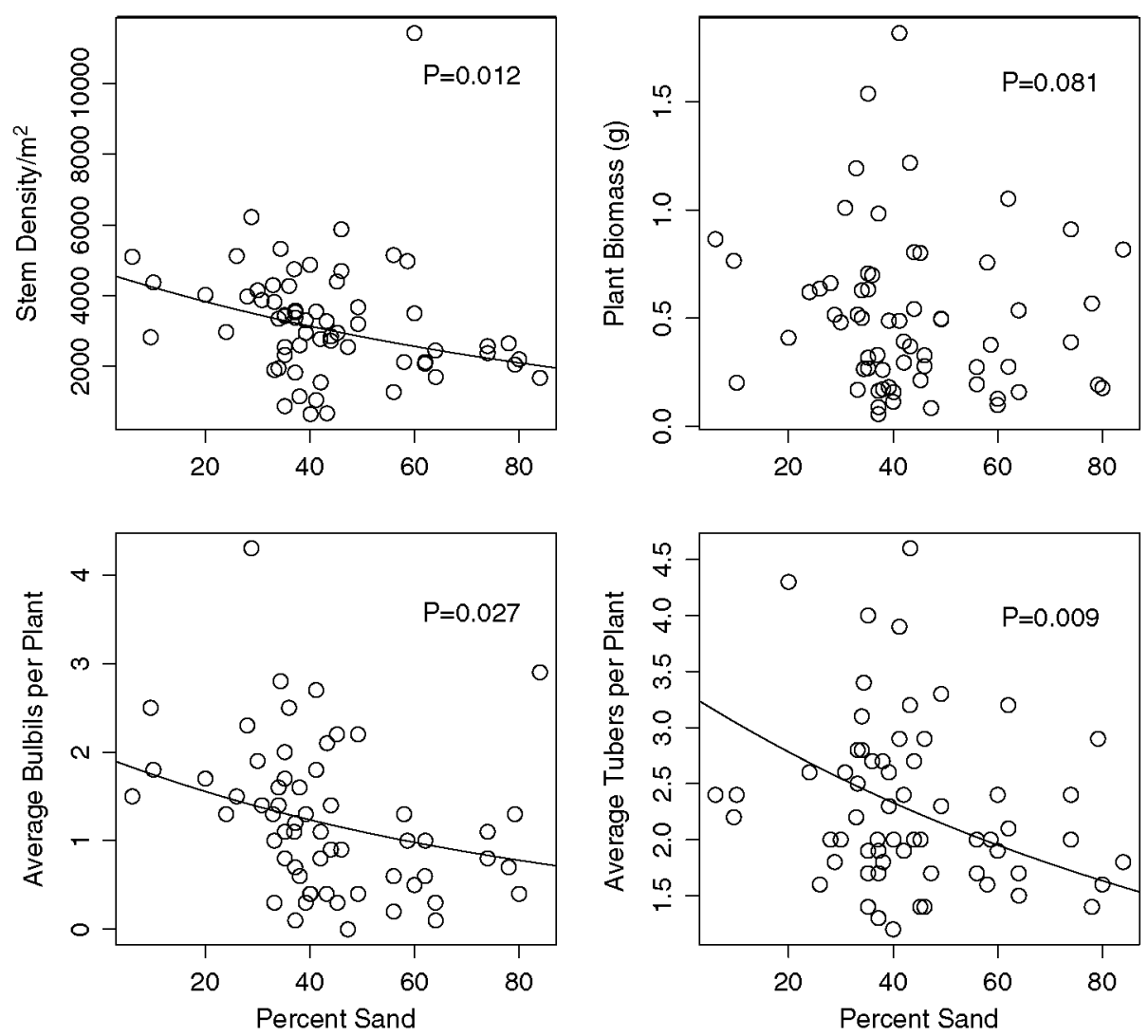

Figure 1. The relationship of Ficaria verno performance to percent sand. In the ficoric verna-focused survey, stem density iupper left) had a significant negative relationship with stem density $(P=0.012$; however, the relationship with plant biomass iupper right) was not significant ( $P=0.081$ ! . The average numbers of bulbils $p e r$ plant $\{$ lower left) had a significant negative relationship with percent sand $P=0.012$ ), as did the average number of tubers per plant $\{$ lower right, $P=0.009$ l. Lines shown are regression lines from the fitted model for statistically significant relationships.

In plots with $F$, verna present, percent cover in the large-scale survey was significantly higher at $30 \mathrm{~m}$ than at $0 \mathrm{~m}(z=3.77$, $\mathrm{P}<0.001$, slope $=0.218$; Figure 4) and significantly negatively related to light availability $(z=-5.22, \mathrm{P}<0.001$, slope $=-0.164)$. Plant biomass maxima were generally found at locations of low slope gradients of below $10^{\circ}$. The model of $F$. verna biomass included nonsignificant relationships with distance from the river $(F(2,33.9)=0.0036, \mathrm{P}=0.997)$ and a nonsignificant negative relationship with log-transformed slope $(\mathrm{t}=-1.82, \mathrm{df}=28.15$, $\mathrm{P}=-0.079$, slope $=-0.486$ ).

\section{The Relationship of Ficaria verna Abundance and Reproduction with Distance and Enviromental Variables}

Soil characteristics are important driving forces behind $F$. verta success, with significant negative relationships found between $F$. vema abundance and reproductive output and percent sand and in some cases also with $\mathrm{CEC}$. We found relatively consistent relationships with percent sand across the response variables, and this result may be driven by the fact that lower percent sand is associated with higher soil moisture. Although percent sand and $\mathrm{CEC}$ are often negatively related to each other, in our study, they were only weakly related to each other, perhaps because soil organic matter is also important in determining CEC. We were unable to simultaneously test correlated variables; soil moisture and nitrogen were inversely correlated with percent sand and were not a focus of our analyses. Higher performance in less sandy soils may also be due to elevated calcium levels; soil calcium has been linked to increased $F$. verna abundance and reproduction, as it has for several other invasive species (Harrison 1999; Howard et al. 2004).

While some sites did have higher $F$. verna abundance and reproduction at intermediate distances, as indicated by higher maximal values at intermediate distances, overall, we did not observe significantly higher $F$. verna abundance and reproduction at intermediate distances. One possible reason is that flooding from the river was not the only major disturbance at several sites. There were several trails and swales that generally occurred around the $10-$ to $20-\mathrm{m}$ quadrats, and these tended to have poor plant performance. Anthropogenic disturbances were avoided as much as possible, yet the Rocky River Reservation is well frequented by the public, making certain disturbances unavoidable. This resulted in some intermediate distance plots also experiencing high levels of disturbance.

Soil $\mathrm{pH}$ was not in most final models due to a lack of strong relationships with $F$. verna abundance and reproduction, but there was a negative relationship between soil $\mathrm{pH}$ and plant biomass that was marginally significant, $(P=0.056)$. This result was unexpected, because generally, $F$. verna performance appeared to be higher at higher $\mathrm{pH}$ values. It may be that some of the $\mathrm{pH}$ levels in our study were higher than $F$. verna would prefer. According to previous work, $F$, verna requires a $\mathrm{pH}$ range of 4.4 to 6.9 (Axtell et al. 2010). The F. verna populations during the 2-yr observational study were found growing in soils with $\mathrm{pH}$ levels from 

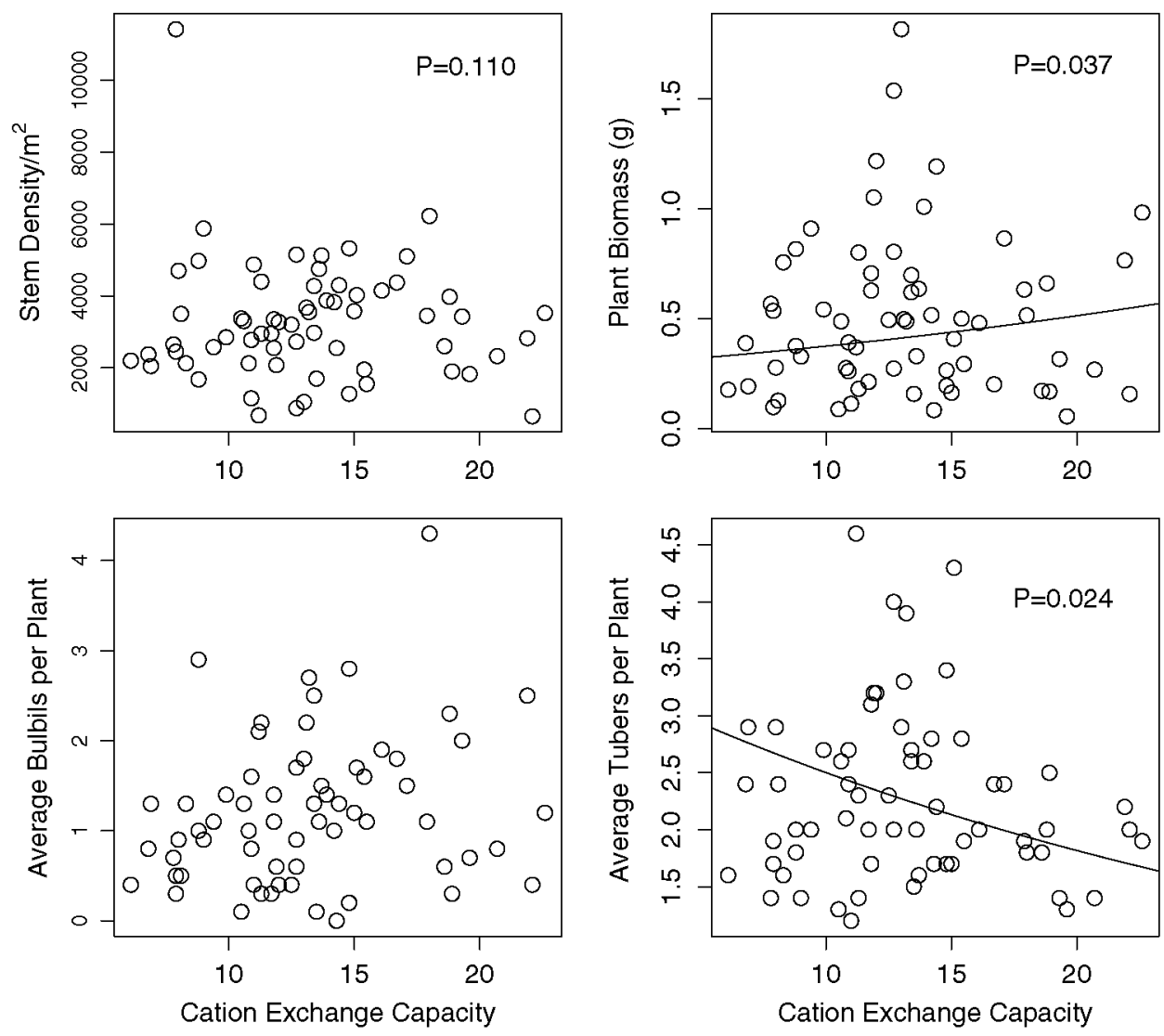

Figure 2. The relationship of Ficoria verna performance and CEC. In the $f$. verno-focused survey, there was a nonsignificant negative relationship with stem density iupper left, $P=0.11$ ), and a significant negative relationship with plant biomass \{upper right, $P=0.033$, as well as a significant interaction of $p H$ and $C E C . C E C$ was not included in the final model with average bulbils, due to a lack of a significant relationship, but it did have a significantly negative relationship with the average number of tu bers produced (lower right, $P=0.024)$. Lines shown are regression lines from the fitted model.

4.49 to 7.35 . This elevated $\mathrm{pH}$ range may be attributed to the parent rock material in the Cleveland area, which can result in soil $\mathrm{pH}$ above 7.0. In general, higher-pH areas are considered to be at greater risk of invasion (Tsui et al. 2004). Increasing soil acidity allows for increased availability of phosphorous uptake, yet alkaline elements such as potassium, magnesium, calcium, and sodium are lost (Kidd and Proctor 2001).

Although PAR was not strongly associated with higher $F$. verta abundance and reproduction in the $F$. verna-focused survey models, percent cover had a negative relationship with light in the large-scale study. Ficaria verna is most often found in shaded sites and less commonly found in full sun on open ground, unless soil moisture levels are sufficient (Axtell et al. 2010). Too much direct sunlight may also lead to withering in populations, and thus slightly shaded areas seemed to lead to more vigorous populations in the field.

Slope had a significantly negative relationship with percent cover. It was clear in field sites that, although $F$. verna can be found on very steep slopes, the plant population is increasingly sparse and patchy with increasing gradients. Steep slopes generally have dry, shallow soils, and $F$. verna prefers moist, fertile floodplain (Axtell et al. 2010). Invasive plants typically occur most frequently on flatter slopes, along with other herbaceous plant species (Underwood et al. 2004).
Additionally, several of our candidate variables did not have a close enough relationship to $F$. verna abundance and reproduction to be included in any final models. For example, in the large-scale survey, aspect (southness and eastness) was not included in any final models. Similarly, canopy cover was also not in any final models. Canopy cover may be less important for $F$. verna performance, because its peak growing season occurs before leaf-out.

Variations in weather patterns from year to year can play a significant role in observational studies of this nature. Water-level fluctuations can influence effects on plant abundance and reproduction, allowing some plant species to thrive in areas of highfrequency flooding while restricting others to higher elevations (Leyer 2005; Van Eck et al. 2004). There were large temperature and precipitation differences from 2015 to 2016; the 2015 winter was significantly more severe, with temperatures reaching much colder levels with greater amounts and sustained snow and ice cover. The cold winter rebounded sharply into a warmer spring to summer transition in comparison to 2016, causing sharp and erratic flash floods after ice melt in 2015, potentially spreading the $F$. verna propagules to a greater degree. We observed similar plant biomass with higher densities and bulbil counts in 2016 than in 2015. Ficaria verna prefers cooler growing conditions and starts to senesce, with tubers delaying their growth, when temperatures consistently hit or exceed $20 \mathrm{C}$ (Kertabad et al. 2013). This implies 

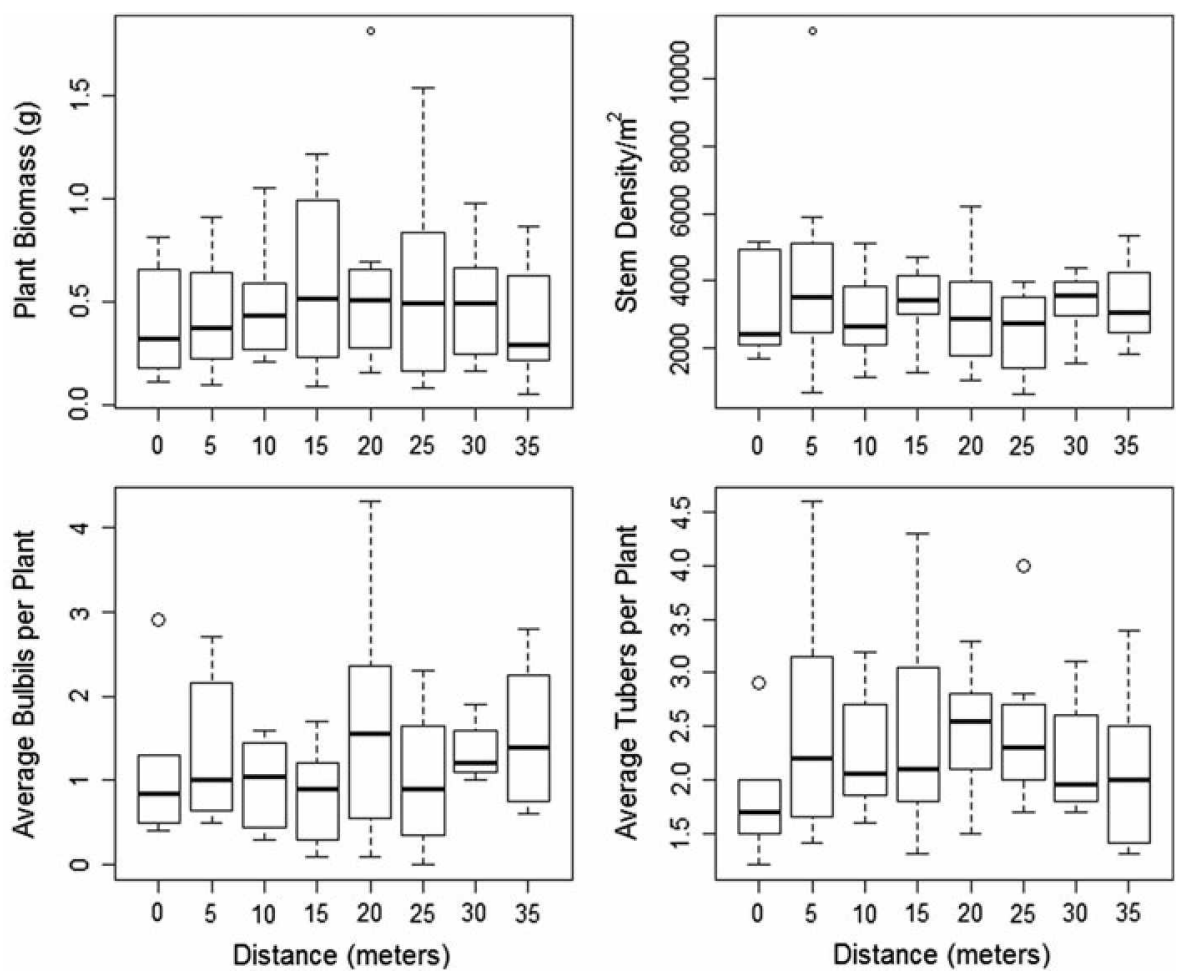

Figure 3. The relationship of Ficorio verno performance with distance from the river. Plant abundance and reproduction in the $F$. verno-focused survey was variable as a function of distance to the river, and the median was generally lower close to the river, and to some extent farther from the river. None of the metrics of $f$. verna abundance and reproduction had significantly different means at different distances.

that weather conditions may have played a large role in the increased reproductive output in 2016. In general, spring ephemerals prefer cooler growing conditions, which result in longer leaf longevity (Badri et al. 2007; Yoshie 2008).

Although our study did not focus on leaf litter, variable leaf litter depths are common to riparian corridors due to the variation in flooding frequency and intensity (Masters and Emery 2015a). While a lack of litter and deep litter both decreased $F$. verna biomass, bulbil production was not different across treatments, and seed production only decreased in deep litter of $20 \mathrm{~cm}$ (Masters and Emery 2015a). This maintenance of reproductive output across a variety of leaf litter depths may provide an advantage over native species competing for resources (Masters and Emery 2015a).

During the 2-yr observational study in Rocky River Reservation, $F$. verna produced no seeds in our study plots, and we only observed a few plants outside the study transects producing seeds. This suggests that F. verna populations in Rocky River do not rely heavily on sexual reproduction. Resource allocation in this invasive favors asexual reproduction through high production of tubers and aboveground bubils. Vegetative diaspores have been hypothesized to be physiologically advantageous during germination (Jung et al. 2008). This may be a more effective method for dispersal, as germination rates have resulted in higher percentages for bulbils than seeds, with $81 \%$ germination for bulbils in comparison to $71 \%$ germination for polyploid seeds and $18 \%$ for diploid seeds (MarsdenJones 1935). One drawback of investment into tubers and bubils is the high resource cost needed to produce the large structures, yet field observations show that this strategy does lead to large infestations of $F$, verna.

The degree to which $F$. verna produces seeds, bulbils, and tubers is variable and may depend on which subspecies is present. Bulbils are thought to have evolved in response to limited pollinator visitations in moist habitats mainly caused by a shady living environment (Deng et al. 2013). It appears that bulbil germination rates by the end of the year are extremely high, indicating little innate dormancy in the field. Due to trade-offs in resource allocation, an increase in clonal investment is linked with decreased allocation to sexual reproduction (Barrett 2015). Extensive vegetative dispersal and clonal growth can negatively impact the functioning of sexual polymorphisms, which can relate to single mating groups with consequential effects on mating and fertility (Barrett 2015). Sexual dysfunction and loss of sexual reproductive ability can result from populations in which clonal propagation is the dominant form of dispersal, which aids mutations that decrease fertility (Barrett 2015).

In conclusion, management will be most effective in combating F. verna populations by targeting sites where high reproductive output, most often in the form of bulbils, is likely. Soil characteristics appear to play a large role in driving population performance and should be considered to help prioritize the allocation of resources for management. Besides reproductive potential, it is also important to consider where spread is most likely to occur. Areas close to the river are extremely important with regard to population spread and may also require management. Overall, the highest-priority sites are in floodplains with less sandy soils and a low slope gradient. 

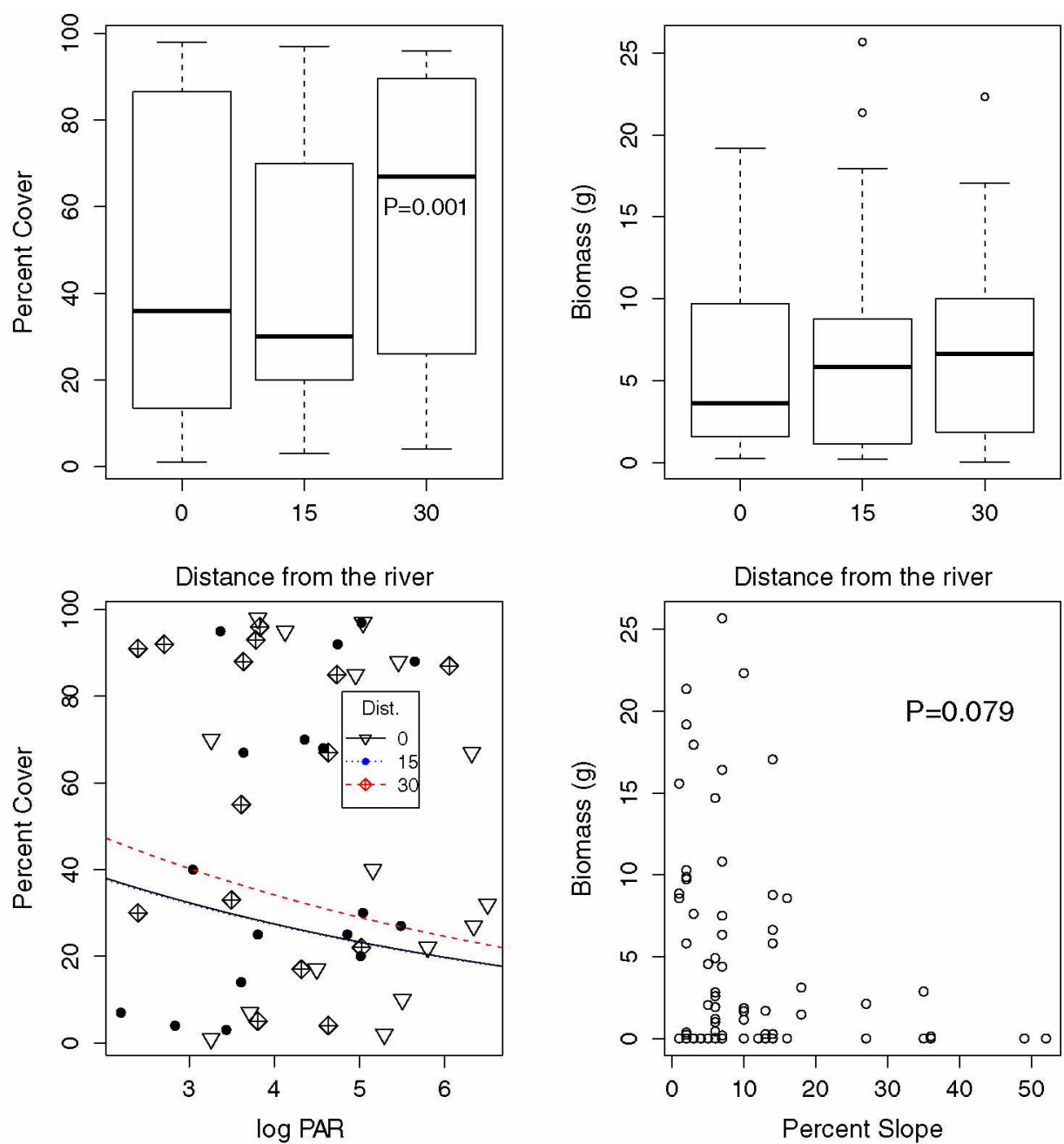

Figure 4. Ficorio verno abundance and reproduction in the large-scale survey. Ficorio verno percent cover was higher $30 \mathrm{~m}$ from the river \{upper right, $\mathrm{P}=0.001$ l and was lower where PAR was higher $\{$ lower left, $P<0.001$ l. The regression lines in the lower left panel show the relationship between percent cover and PAR separately for the three distances from the river; the 30 - $\mathrm{m}$-distance line has higher percent cover, while the 0 - and $15-\mathrm{m}$ lines are nearly indistinguishable. Plant biomass was not significantly higher farther from the river, and the final model included a nonsignificant relationship between slope and biomass $\{\mathrm{P}=0.079$ ).

Acknowledgments. Jennifer Hillmer. Patrick Lorch, Julie Wolin, and Pete Clapham contributed helpful insights to this project. Megan Palfalvi, Dolly Funk, Rene Kizys, Morgan Moscarillo, Allison Paolucti, Kevin Darragh, Robin Hajek, Daniel Khanin, and Alix Kosmala assisted with field and lab work. JPK wishes to acknowledge funding trom the Ohio Invasive Plants Council. No conflicts of interest have been declared.

\section{References}

Arizaga S. Ezcurra E (1995) Insurance against reproductive tailure in a semelparous plant: bulbil tormation in Agare macroacantha tlowering stalks. Decologia 101:329-334

Axtell AE, DiTommaso A, Post AR (2010) Lesser celandine (Ranunculus frcaria): a threat to woodland habitats in the Northern United States and Southern Canada. Invasive Plant Sci Manag 3:190-196

Badri MA, Minchin PE, Lapointe L (2007) Etfects of temperature on the growth of spring ephemerals: Crocus rermus. Physiol Plant 130:67-76

Barrett SCH 2015$\}$ Influences of clonality on plant sexual reproduction. Proc Natl Acad Sci USA 112:8859-8866

Bates D, Maechler M, Bolker B, Walker S (2015) Fitting linear mixed-effects models using Ime4. J Stat Softw $67: 1-48$

Daubenmire RF (1959) A canopy-cover method of vegetational analysis. Northwest Sci 33:43-46
Deng T, Kim C, Zhang D, Zhang J, Li Z, Nie Z, Sun H (2013) Zhengyiat shennongensis: a new bulbiliterous genus and species of the nettle tamily (Urticaceae) from central China exhibiting parallel evolution of the bulbil trait. Taxon 62:89-99

Gee GW, Bander JW (1979) Particle size analysis by hydrometer: a simplitied method for routine textural analysis and a sensitivity test of measurement parameters. Soil Sci Soc Am J 43:1004-1007

Harrison S (1999) Local and regional diversity in a patchy landscape: native, alien, and endemic herbs on serpentine. Ecology 80:70-80

Hillmer J, Garman B (2016) Lesser celandine. Cleveland Metroparks Invasive Plants Atlas. http://cleveland-metroparks.github.io/atlas/contact/contact. html. Accessed: October 1, 2015

Hobbs RJ, Humphries SE (1995) An integrated approach to the ecology and management of plant invasions. Conserv Biol 9:761-770

Howard TG, Gurevitch J, Hyatt L, Carreiro M, Lerdau M (2004) Forest invasibility in communities in southeastern New York. Biol Invasions 6:393-410

Jose S, Singh HP, Batish DR, Kohli RK, eds (2013) Invasive Plant Ecology. Boca Raton, FL: CRC Press. $302 \mathrm{p}$

Jung $F$, Bohning-Gaese $K$, Prinzing A (2008) Life history variation across a riverine landscape: intermediate levels of disturbance favor sexual reproduction in the ant-dispersed herb Ranumculus frcaria. Ecography $31: 776-786$ 
Kertabad S, Mohassel MH, Mahalati MN, Gherekhloo J (2013) Some biological aspects of the weed lesser celandine (Ranumiulus ficaria). Planta Daninha 31:577-585

Kidd PS, Proctor J (2001) Why plants grow poorly on very acid soils: are ecologists missing the obvious? J Exp Bot 52:791-799

Kuznetsova A, Brockhoft $\mathrm{PB}$, Christensen RHB (2017) lmerTest package: tests in linear mixed effects models. J Stat Softw 82:1-26

Leyer I (2005) Predicting plant species' responses to river regulation: the role of water level tluctuations. J Appl Ecol 42:239-250

Lite SJ, Bagstad KJ, Stromberg JC (2005) Riparian plant species richness along lateral and longitudinal gradients of water stress and flood disturbance, San Pedro River, Arizona, USA. J Arid Environ 63:785-813

Mack J (2008) Workplan for Lesser Celandine (Ranumiulus ficaria) Control in Rocky River Reservation. Cleveland, OH: Cleveland Metroparks Technical Report 2008/NR-05. 15 p

Marsden-Jones EM (1935) Ranumiculus frcaria Linn: life-historyand pollination. J Linn Soc Lond Bot 50:39-55

Masters JA, Emery SM (2015a) Leaf litter depth has only a small intluence on Ranumculus ficaria (Ranunculaceae) biomass and reproduction. Am Midl Nat 173:30-37

Masters JA, Emery SM (2015b) The showy invasive plant Ranuncuslus ficaria facilitates pollinator activity, pollen deposition, but not always seed production for two native spring ephemeral plants. Biol Invasions 17:2329-2337

Masters JA, Emery SM (2016) Do multiple mechanisms drive the dominance of an invasive plant (Ranumisius ficaria. Ranunculaceae) along an urban stream? J Torrey Bot Soc 143:359-366

Mortensen, DA, Rauschert ESJ, Nord AN, Jones BP (2009) The role of roads in plant invasions. Invasive Plant Sici Manag 2:191-199
Porazinska DL, Bardgett RD, Blaauw MB, Hunt HW, Parsons AN Seastedt TR, Wall DH (2003) Relationships at the abovegroundbelowground interface: plants, soil biota, and soil processes. Ecol Monogr 73:377-395

R Development Core Team (2011) R: A Language and Enviroment for Statistical Computing. Vienna, Austria: R Foundation for Statistical Computing

Roxburgh SH, Shea $\mathrm{K}$, Wilson $\mathrm{J}$ (2004) The intermediate disturbance hypothesis: patch dynamics and mechanisms of species coexistence. Ecology $85: 359-371$

Swearingen JM (2005) Lesser celandine. Plant Conservation Alliance Alien Plant Working Group. https:/www.nps.gov/plants/ALIEn/fact/rafil.htm. Accessed: September 20, 2016

Tsui CC, Chen ZS, Hsieh CF (2004) Relationships between soil properties and slope position in a lowland rain torest of southern Taiwan. Geoderma 123:131-142

Underwood EC, K'linger R, Moore PE (2004) Predicting patterns of non-native plant invasions in Yosemite National Park, California, USA. Divers Distrit, $10: 447-459$

Van Eck WiH, Van de Steeg HM, Blom CW, De Froon H (2004) Is tolerance to summer flooding correlated with distribution patterns in river floodplains? A comparative study of 20 terrestrial grassland species. Oikos 107:393-405

Venables WN, Ripley BD (2002) Modern Applied Statistics with S. 4th ed. New York: Springer. $497 \mathrm{p}$

Yoshie F (2008) Effects of growth temperature and winter duration on leaf phenology of a spring ephemeral (Gagea lutea) and a summergreen torb (Maitathemum dilatatum). J Plant Res 121:483-492

Zuur AF, Ieno EN, walker NJ, Saveliey AA, Smith GM (2009) Mixed Etitect Models and Extension in Ecology with R. New York: Springer. 529 p 